Revista Geográfica Digital. IGUNNE. Facultad de Humanidades. UNNE. Año 10. № 20. Julio-Diciembre 2013. ISSN $1668-5180$. Resistencia, Chaco

\title{
URBANIZACIÓN E IMPACTOS. PAISAJES RESULTANTES
}

\author{
Prof. Juan Antonio Alberto
}

Panel Ambiente y Sociedad

Presentado en el XIV Encuentro de Profesores de Geografía del NEA

Departamento de Geografía. Facultad de Humanidades. UNNE Resistencia (Chaco). 20, 21 y 22 de septiembre de 2012

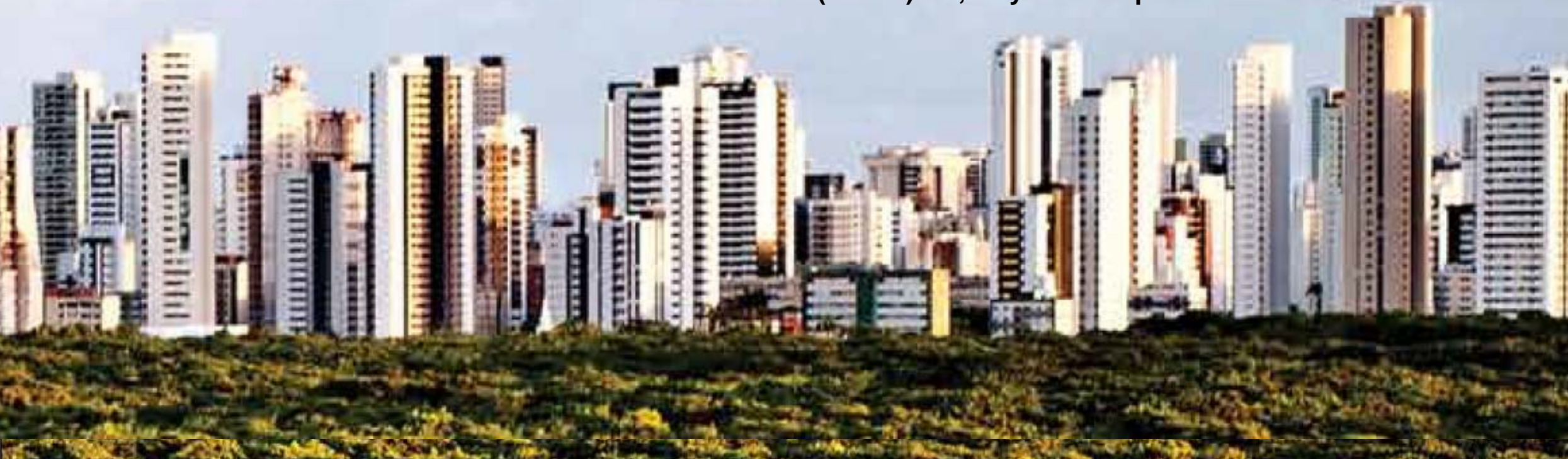

Publicado en formato digital: Prof. Juan Antonio Alberto. Urbañización e Impactos. Paisajes Resultantes . Resúmenes. ReVista Geografica Digital. CUNNE. Facultad

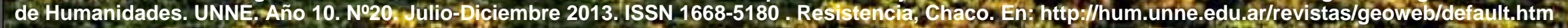




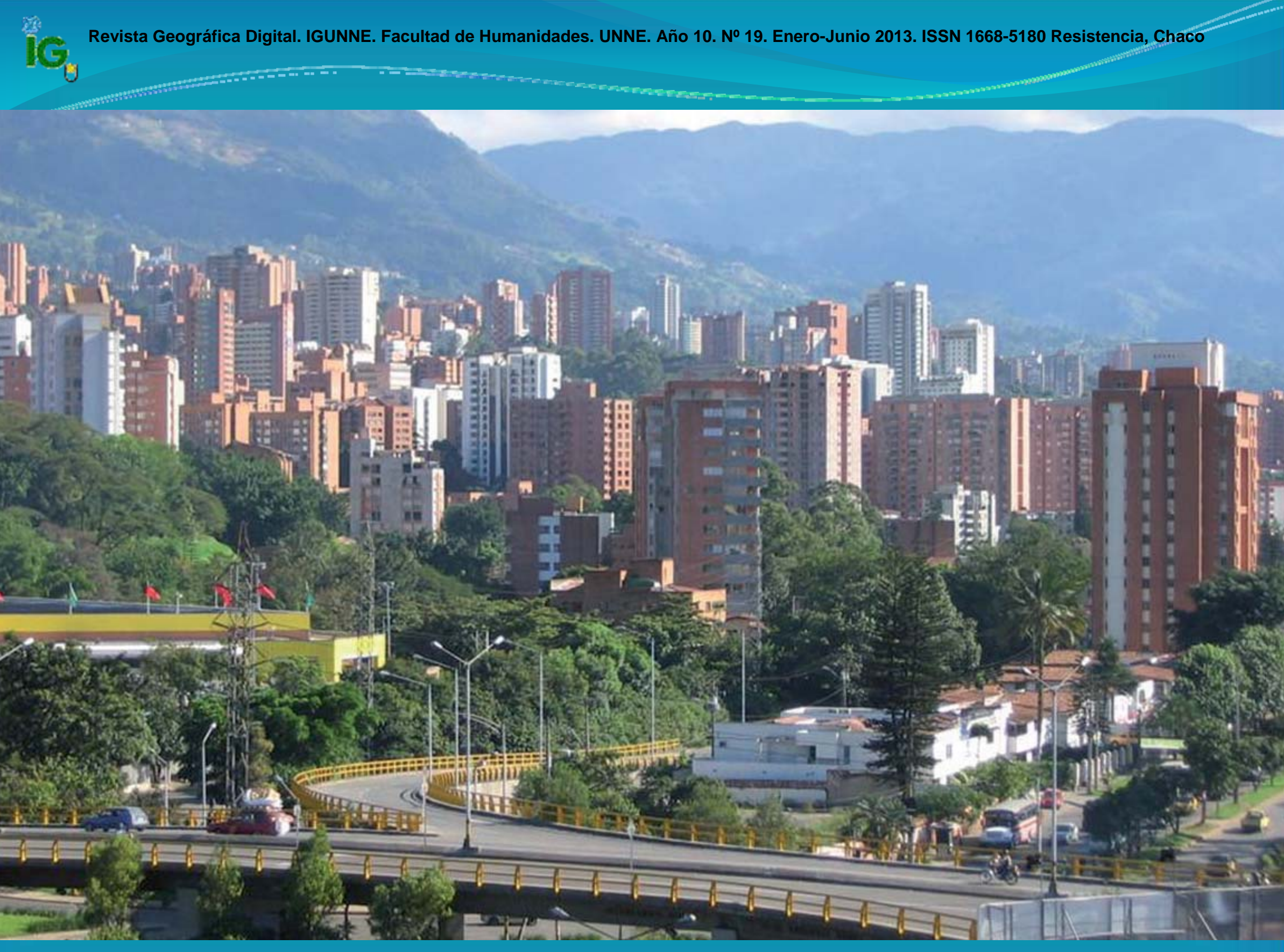

Publicado en formato digital: Prof. Juan Antonio Alberto. Urbanización e Impactos. Paisajes Resultantes . Resúmenes. Revista Geográfica Digital. IGUNNE. Facultad de Humanidades. UNNE. Año 10. №20. Julio-Diciembre 2013. ISSN 1668-5180 . Resistencia, Chaco. En: http://hum.unne.edu.ar/revistas/geoweb/default.htm 

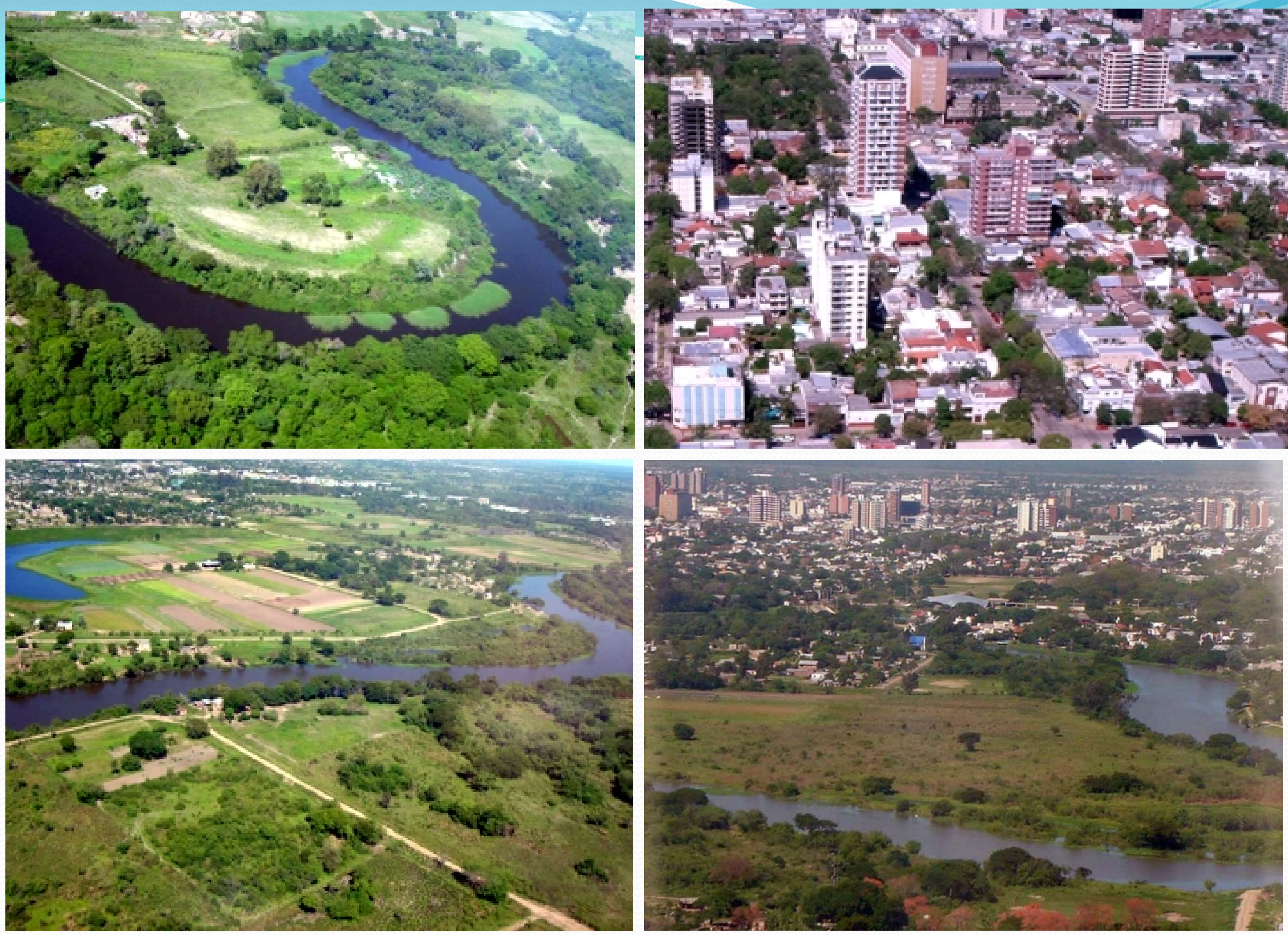

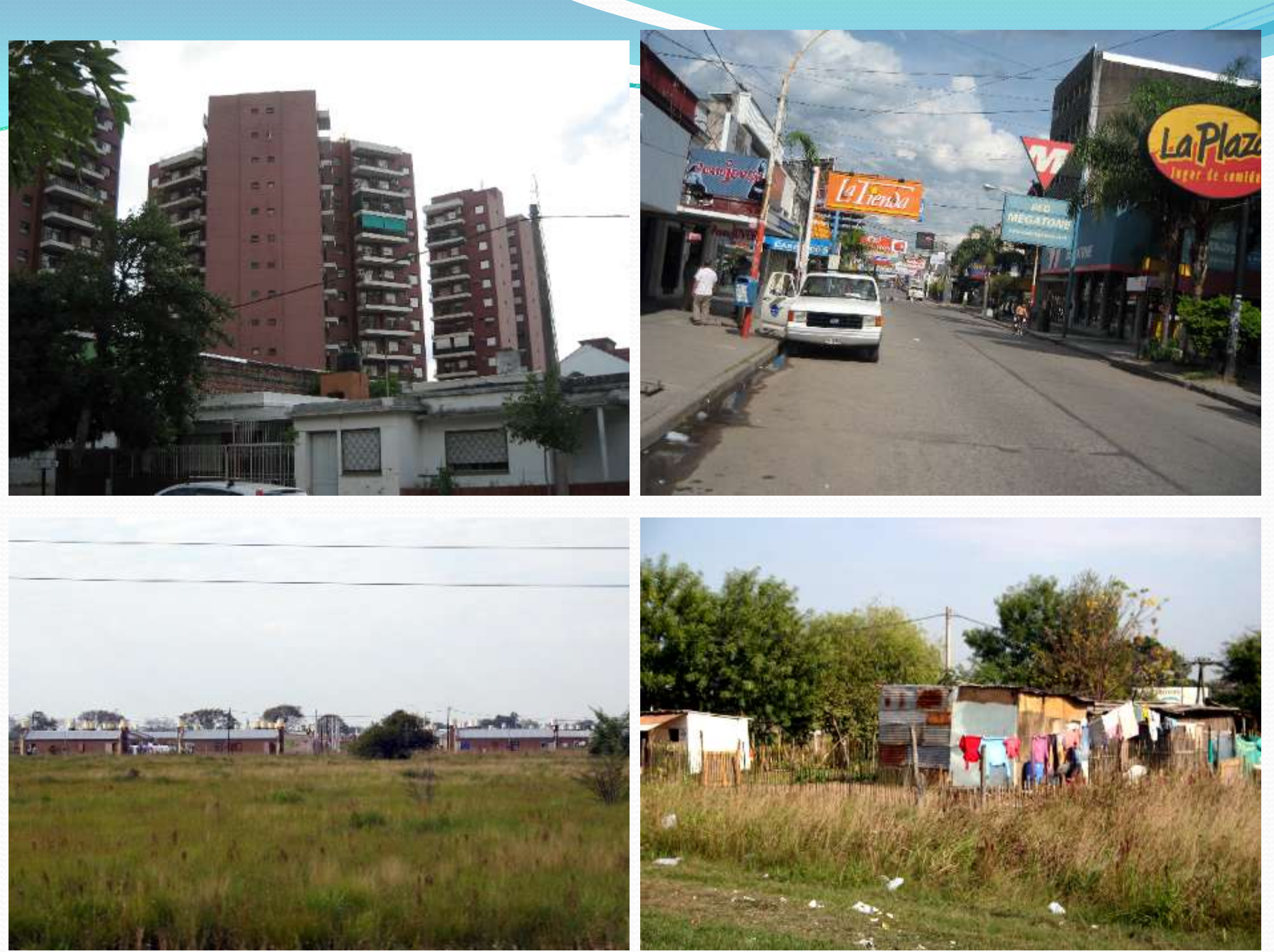
Según Informe 2012 - ONU:

- El 80 \% de la población de América Latina es urbana, superando a la suma de Asia y África.

- 124 millones de pobres habitan las ciudades de América Latina.

- Hay 1 pobre por cada 4 habitantes urbanos.

- La mayoría de las ciudades son insostenible desde el punto de vista ambiental.
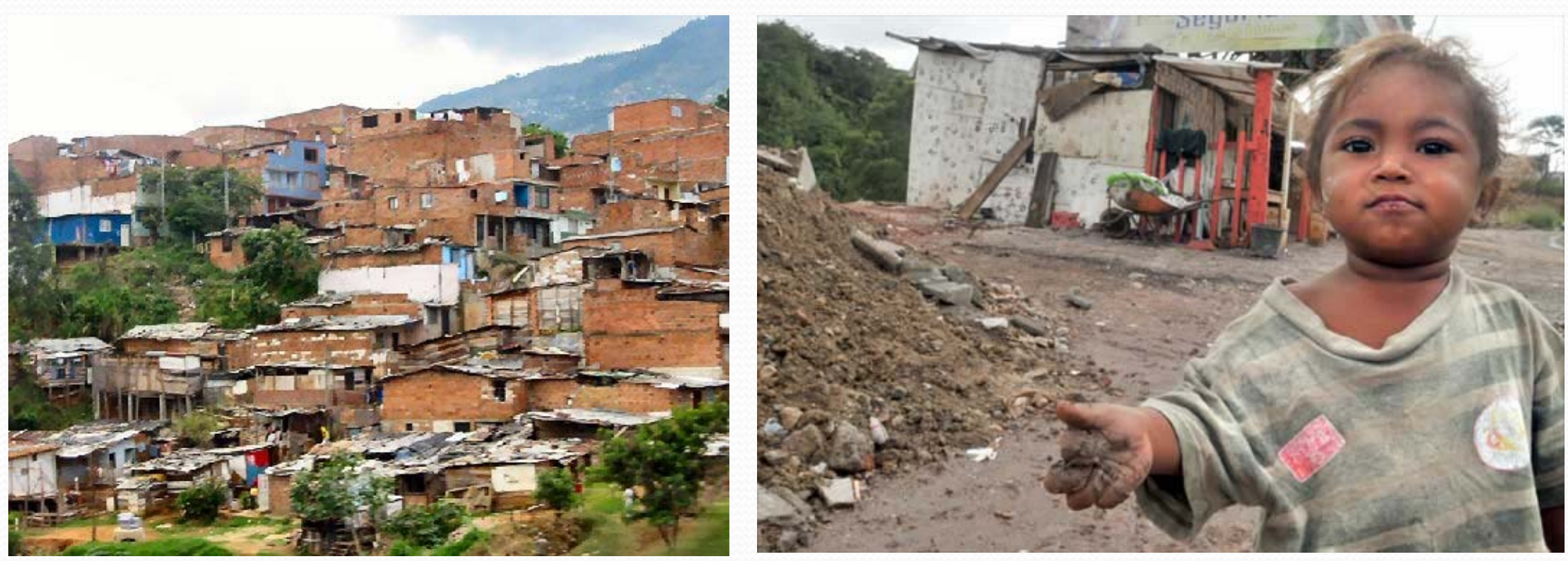

Publicado en formato digital: Prof. Juan Antonio Alberto. Urbanización e Impactos. Paisajes Resultantes . Resúmenes. Revista Geográfica Digital. IGUNNE. Facultad de Humanidades. UNNE. Año 10. №20. Julio-Diciembre 2013. ISSN 1668-5180 . Resistencia, Chaco. En: http://hum.unne.edu.ar/revistas/geoweb/default.htm 
L

Energía Materia prima Agua Población
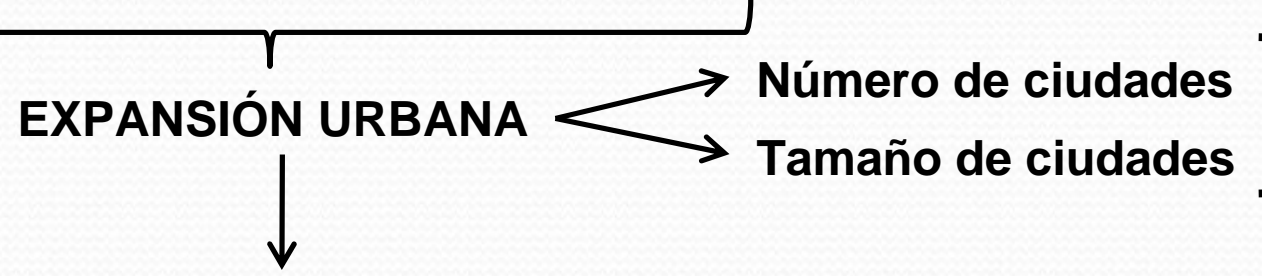

Ocupación y Organización del espacio

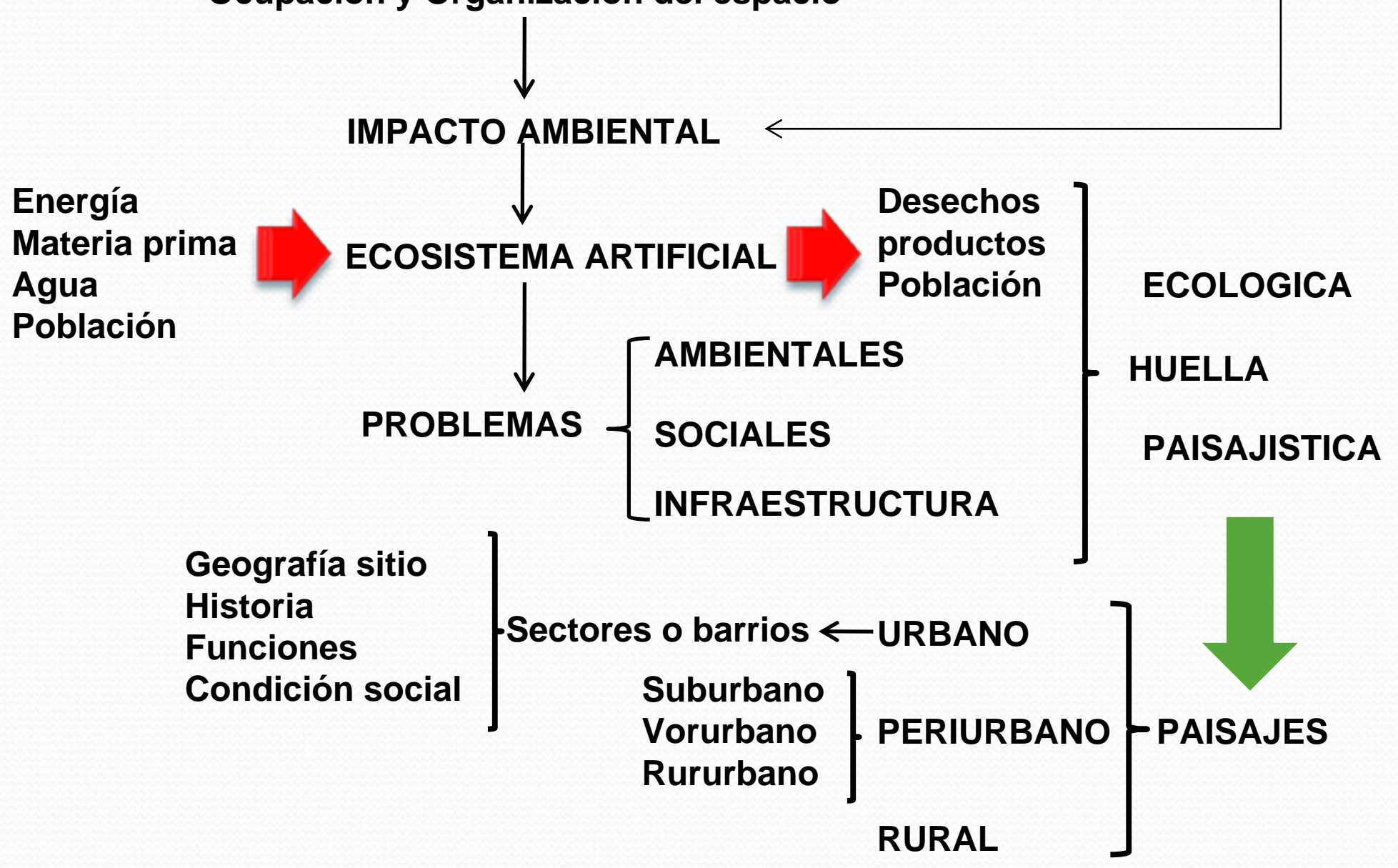




\section{CRECIMIENTO URBANO Y PAISAJE. EL CASO DEL ÁREA METROPOLITANA}

DEL GRAN RESISTENCIA (A.M.G.R.)

Paisajes naturales

con fisonomías de bosques, pastizales sabaneros y ambientes lénticos (lagunas, esteros, cañadas) y lóticos (ríos, riachos y arroyos)

Hoy altamente antropizados
Paisajes rurales

con sus componentes típicos como tambos, granjas, criaderos de pollos y cerdos, corrales para cría y embarque de ganado vacuno, ladrillerías, etc.

Procesos de rururbanización

Paisajes rururbanos

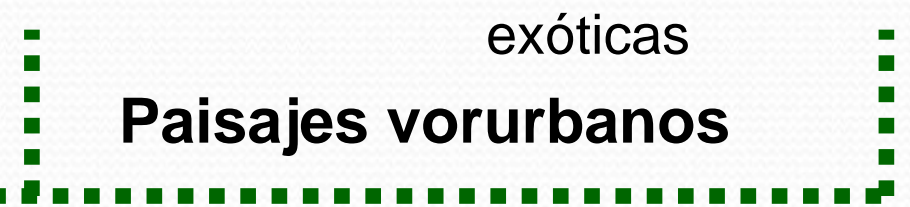

\section{Paisajes de transición}

entre lo natural y rural, entre lo rural y lo urbano y entre lo urbano y lo natural, como baldíos, ambientes ruderales, tierras de barbecho, casas de fin de semana, o de residentes permanentes que gustan de un ambiente más tranquilo y bucólico, también clubes y cementerios parques etc. 


\section{COMPARACIÓN ENTRE ECOSISTEMAS NATURAL Y HUMANO}

\section{ECOSISTEMA NATURAL}

(Pradera, pantano, bosque, sabana, etc.)

- Captura, convierte y almacena energía del Sol.

- Produce oxígeno y consume dióxido de carbono

- Crea suelo fértil

- Almacena, purifica y libera agua dulce gradualmente

- Proporciona hábitat para la vida silvestre

- Filtra y desintoxica contaminantes y productos de desechos, sin encargo alguno

- Generalmente es capaz de automantenimiento y autorrenovación

\section{ECOSISTEMA HUMANO SIMPLIFICADO}

(cultivo de maiz, fábrica, ciudad, casa)

- Consume energía de los combustibles fósiles y nucleares.

- Consume oxígeno y produce dióxido de carbono al quemar combustibles fósiles

- Agota o recubre el suelo fértil

- Con frecuencia agota y contamina el agua, y la libera rápidamente

- Destruye algunos hábitat de la vida silvestre

- Produce contaminantes y desechos que deben ser eliminados a nuestra expensa

- Requiere mantenimiento continuo y renovación a gran costo
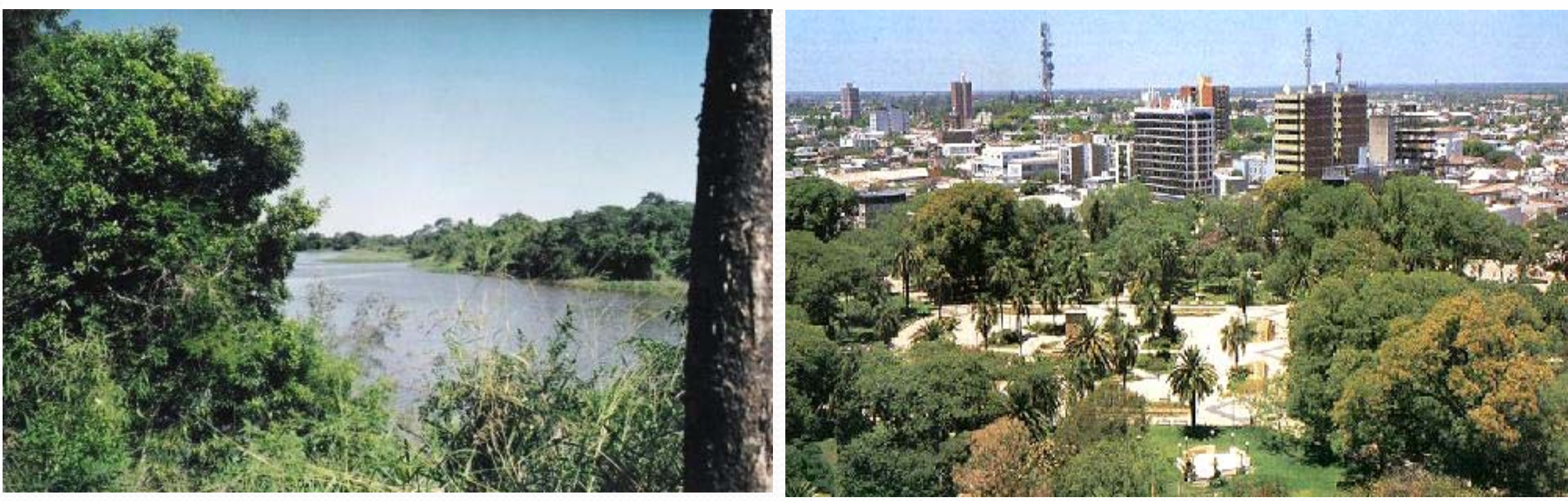


\section{La Ciudad. Ecosistema Urbano}

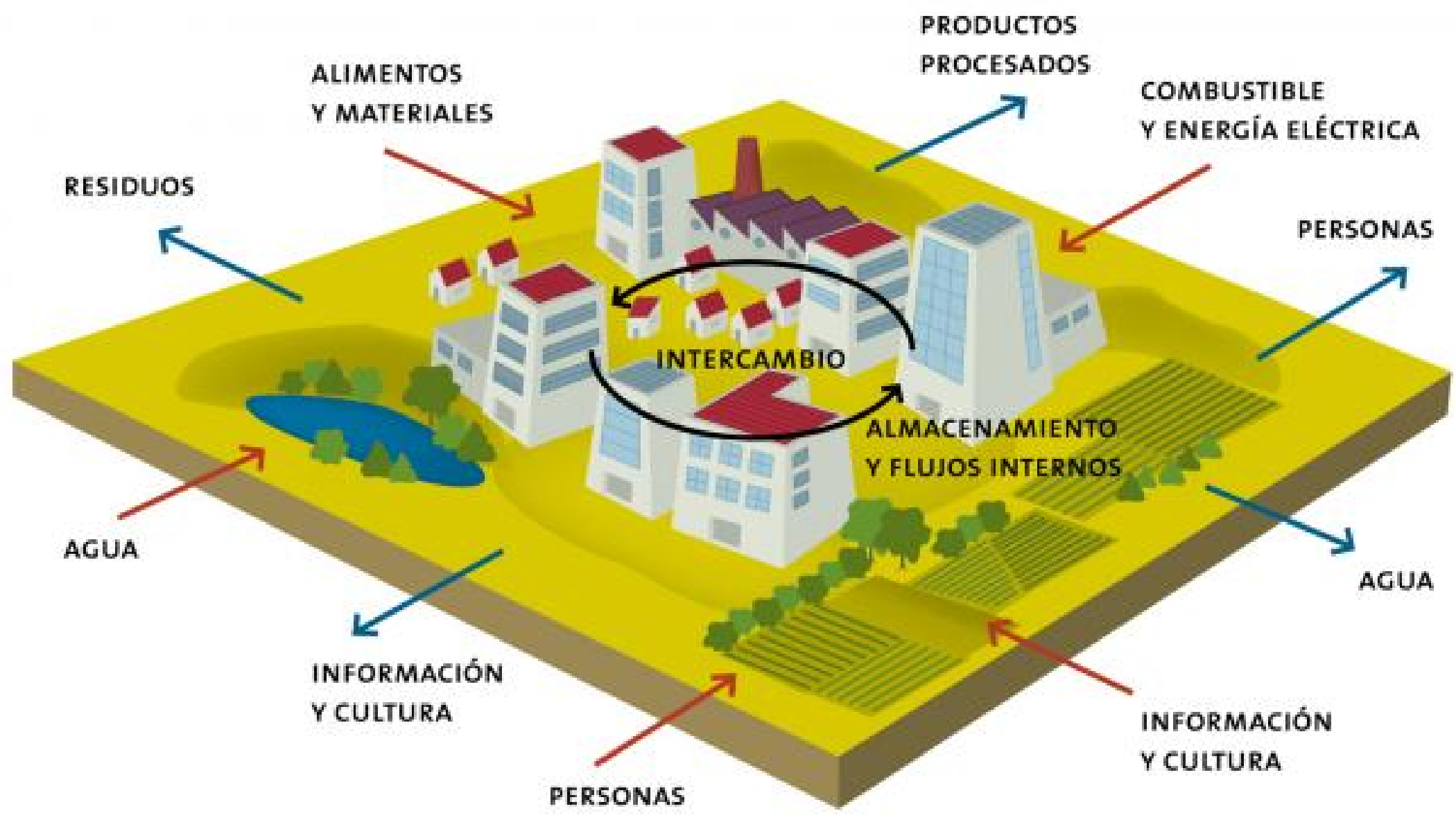




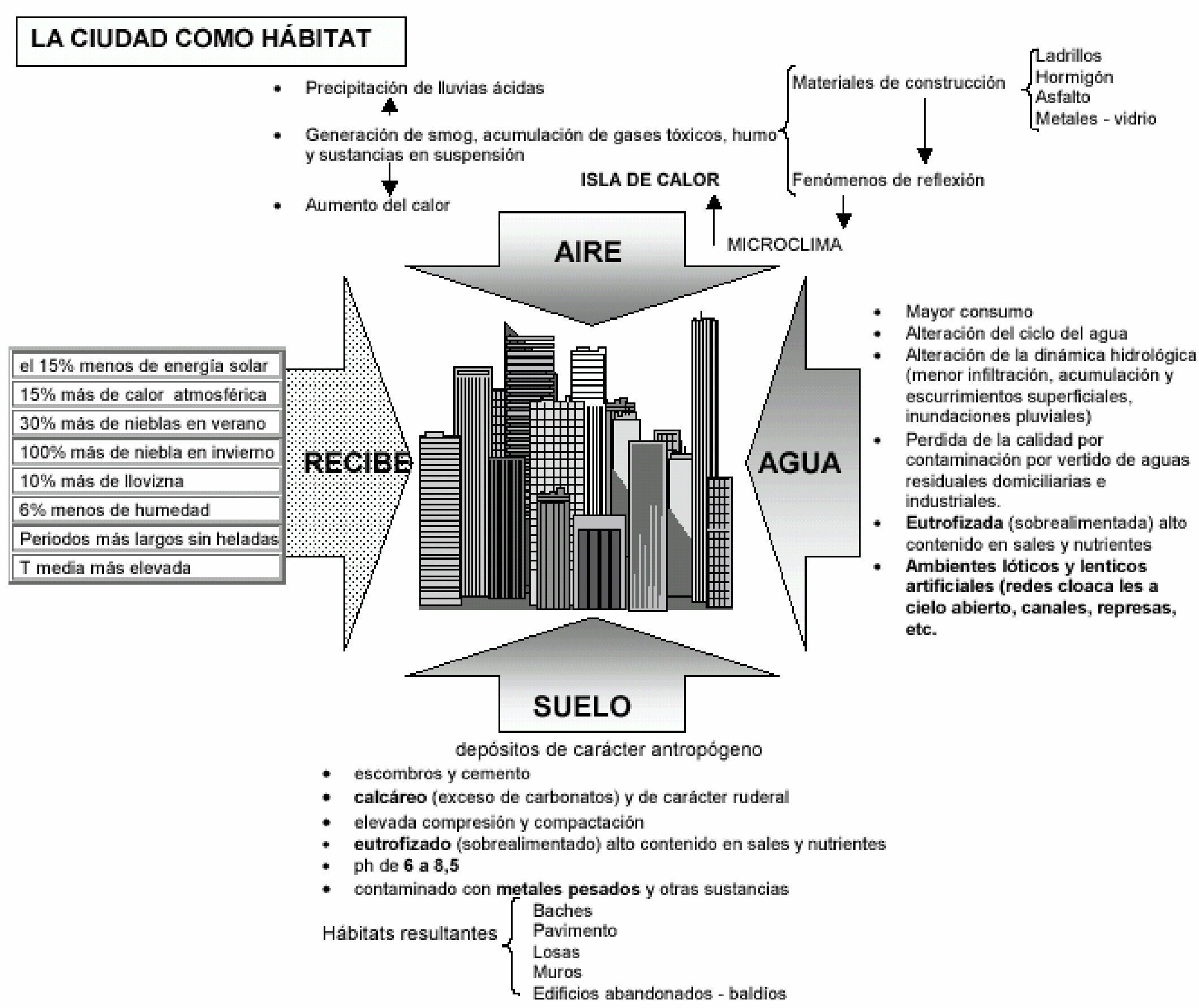

http://geocities.ws/ja_alberto/EcoWeb/ciudad2.html 
POBLACIÓN, CIUDADES Y SOSTENIBILIDAD

La densidad demográfica urbana es un elemento decisivo para la provisión duradera de infraestructuras y servicios públicos y sociales. Es una de las principales ventajas de la urbanización, ya que reduce costos marginales e impactos ambientales, y estimula la cultura y la creatividad.

Las ciudades en la región tienden a la expansión en el territorio, con un crecimiento físico mayor del necesario por crecimiento demográfico.

A nivel local, los patrones de ocupación y desarrollo urbanos están lejos de ser sostenibles.

Muchas ciudades han crecido desordenadamente, sin adoptar criterios ambientales.
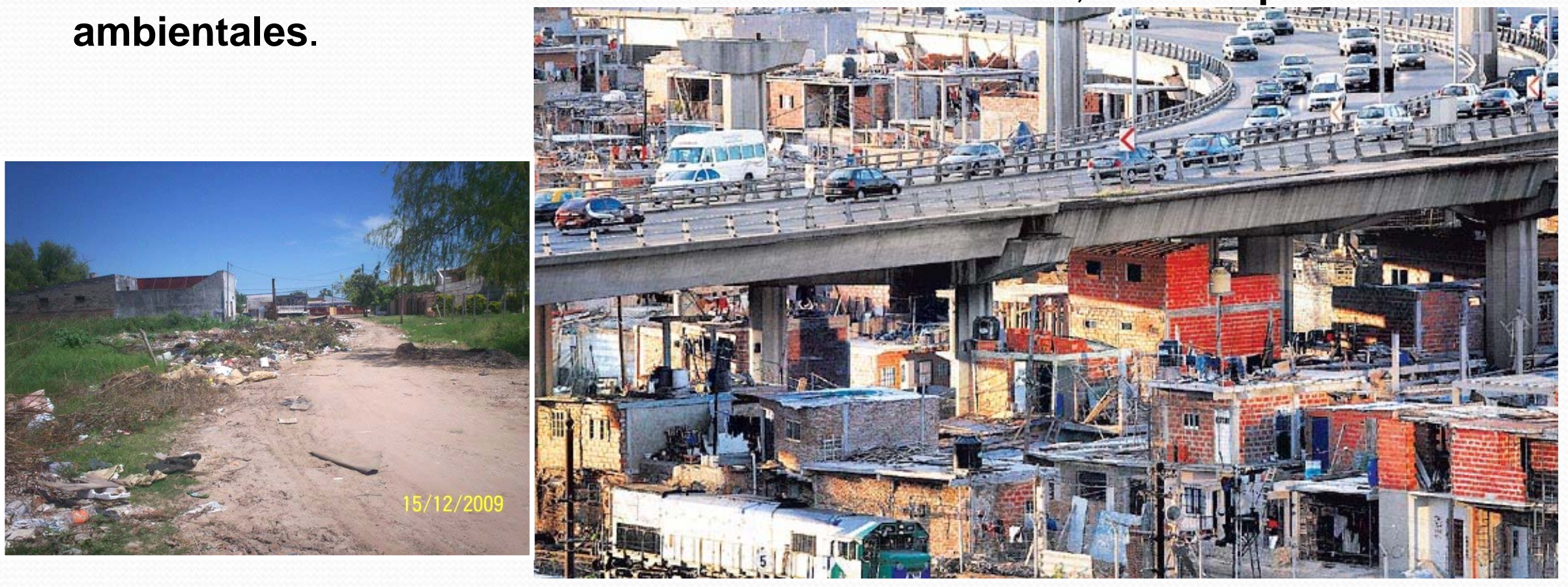


\section{POBLACIÓN, CIUDADES Y DESECHOS}

Los ecosistemas urbanos y su periferia también sufren de la disposición inadecuada de desechos urbanos.

La descomposición de los residuos sólidos produce lixiviados que contaminan fuentes de agua superficiales y subterráneas, y emisiones de metano que deterioran la calidad del aire. Los vertederos no controlados son fuente de propagación de enfermedades trasmisibles por insectos, roedores y aves; además, pueden causar inundaciones, ya que los desechos bloquean, con frecuencia, vías fluviales y canales de desagüe. En las ciudades, también representa una preocupación importante el volumen de escombros generado.
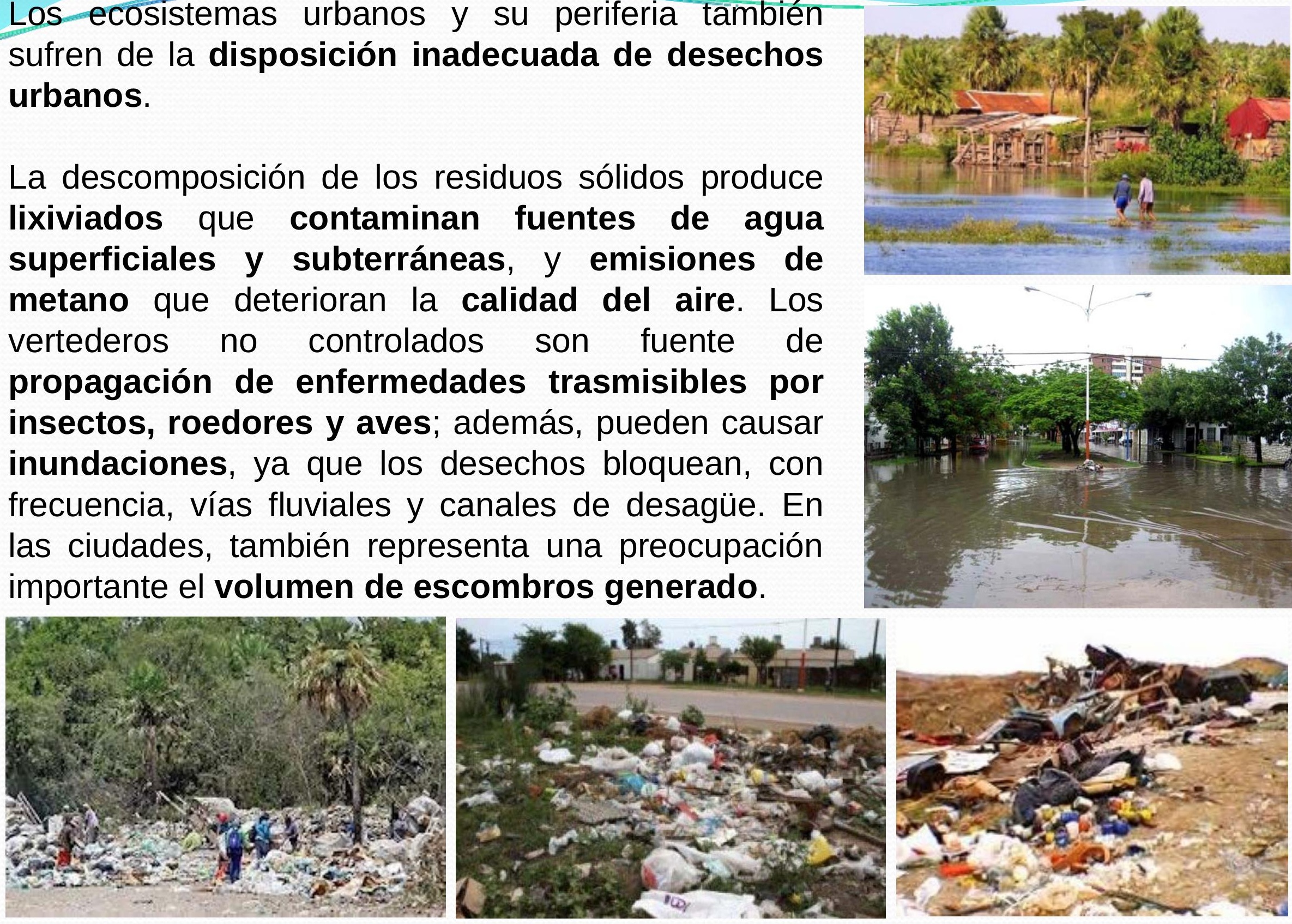
De acuerdo con la agencia de protección Ambiental (Environmental Protection Agency, EPA) de los Estados Unidos, $70 \%$ de la contaminación de los arroyos y lagos proviene de las aguas pluviales. Cuando llueve (o se derrite la nieve en el invierno), el agua baja, recorre caminos y atraviesa varios lugares antes de terminar en los desagües pluviales y arroyos. En este trayecto acumula fertilizantes, pesticidas, residuos de petróleo y muchos productos químicos, tanto de empresas como de habitantes de los diferentes lugares

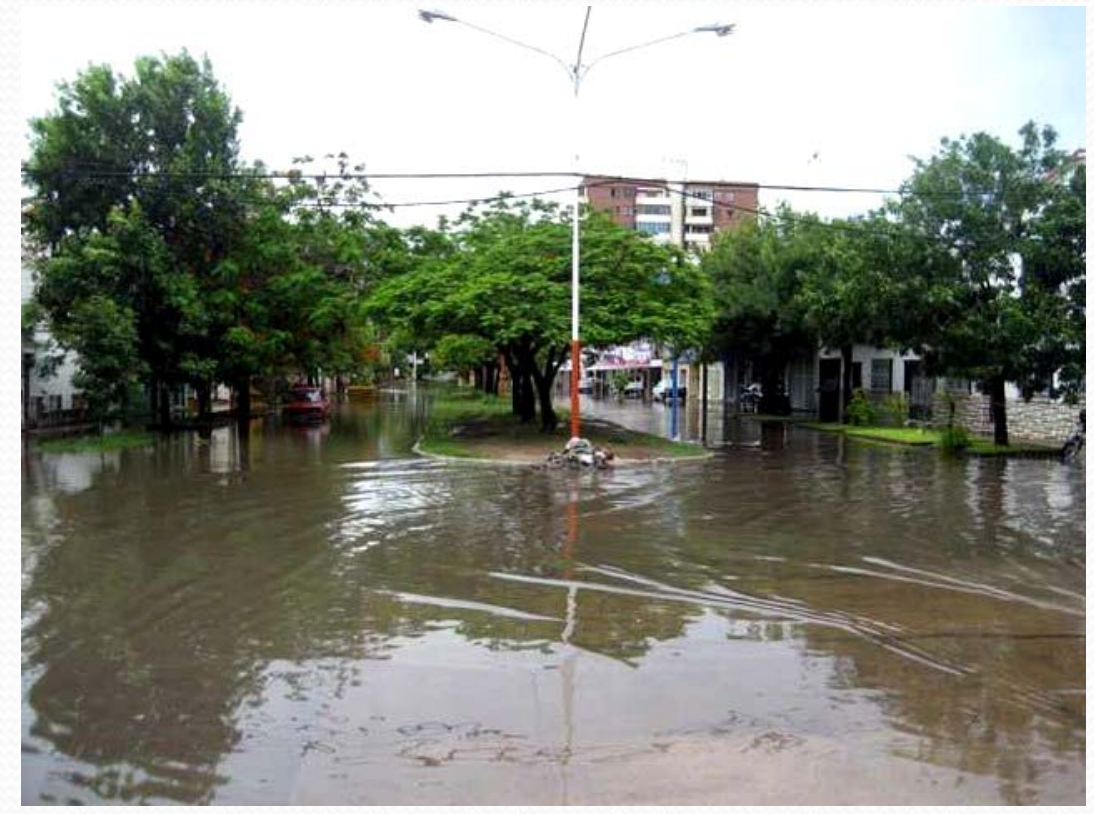

Resistencia, Belgrano y Salta. 24/11/2009

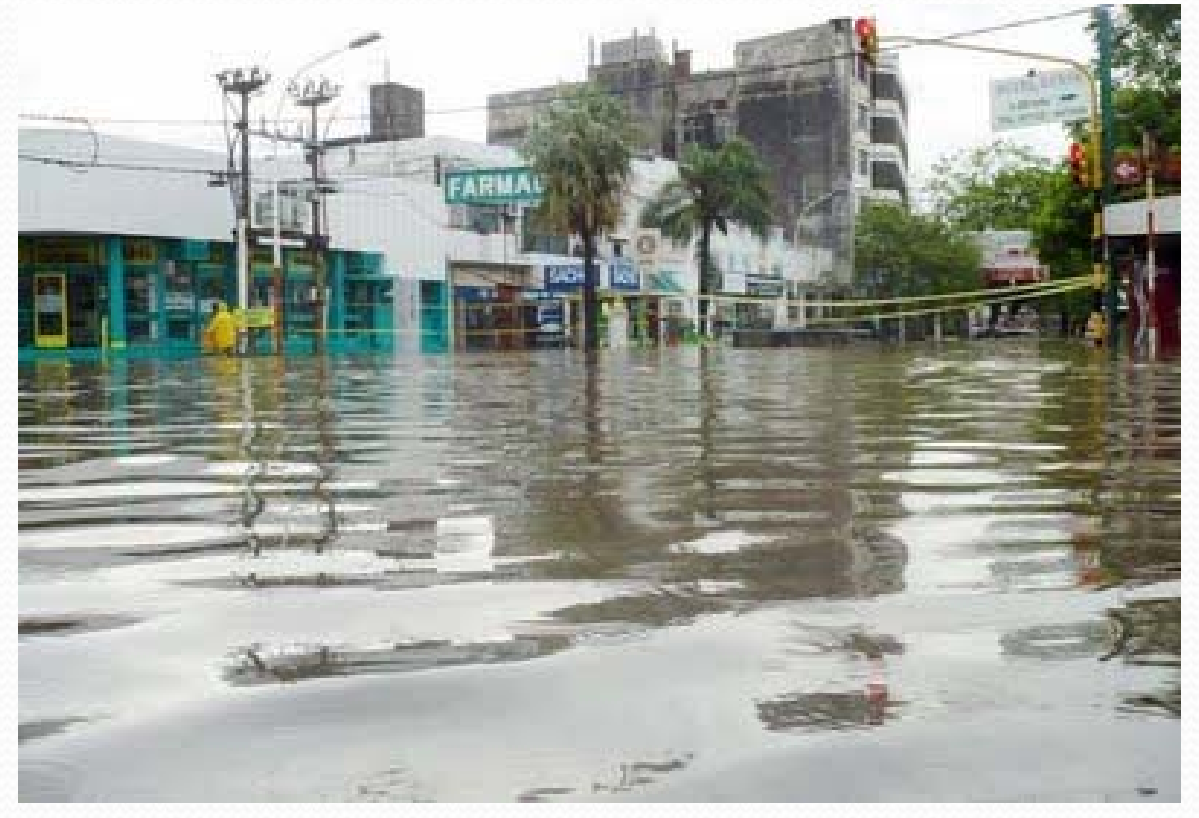

Resistencia, 25 de mayo y Necochea. 24/11/2009 

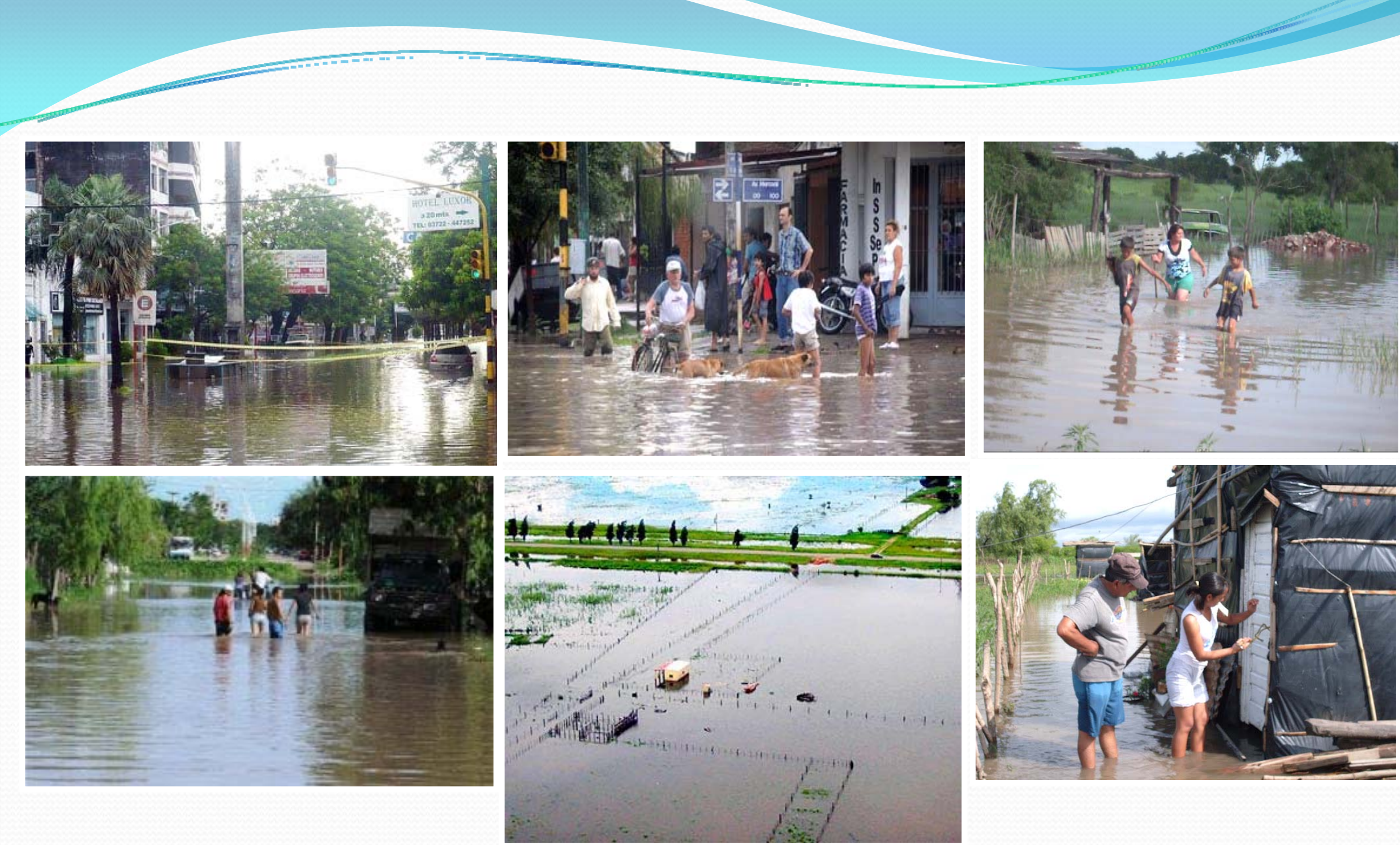

Fotos: Miguel Angel Romero /Diario Norte/Momento24/Infobae/La Tercera.cl/Perfil.com http://diarionala.blogspot.com.ar/2009_11_01_archive.html 


\section{POBLACIÓN, CIUDADES Y ÁREAS VERDES}

Desde el punto de vista ambiental, el tipo de suelo que se ocupa y la forma de hacerlo es tan importante como la cantidad de suelo ocupado.

Una configuración urbana que preserve y extienda la estructura ecológica, tejiendo corredores biológicos a lo largo de su territorio, reduce el impacto negativo del desarrollo urbano sobre los ecosistemas y ayuda a preservar la biodiversidad5. Con la creciente conciencia ambiental, numerosas ciudades han adoptado programas de conservación, educación o reforestación, aunque no siempre con el mismo alcance.

Entre los planes innovadores figura el de corredores biológicos urbanos, creado puentes naturales entre distintas áreas naturales de la ciudad para preservar la fauna y la flora del medio ambiente urbano, y reforzar las funciones ecológicas que cumplen.

La Organización Mundial de la Salud recomienda que las ciudades dispongan como mínimo entre 9 y $11 \mathrm{~m}^{2}$ de área verde por habitante.

Con frecuencia, se suman al indicador áreas verdes localizadas en la periferia, que no forman parte de la inmediatez ambiental y mucho menos de la vida urbana cotidiana.
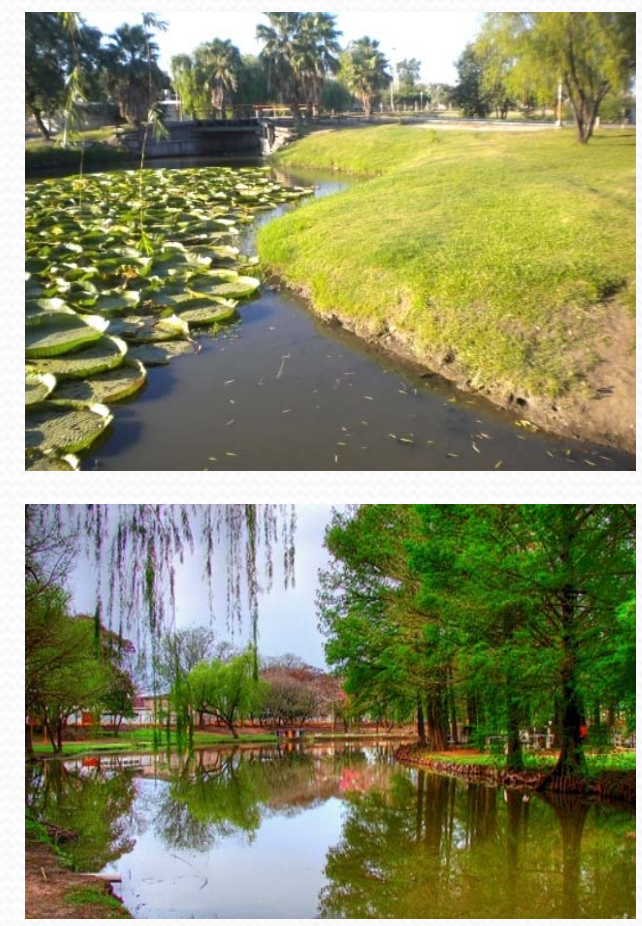

http://entercerapersona.com.ar/2011/page/2/

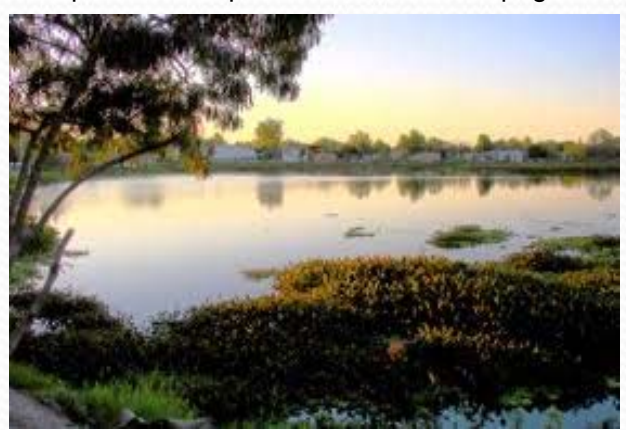


El crecimiento de las ciudades contribuye a la deforestación, pero su participación es insignificante comparada con la expansión de la frontera agrícola y ganadera.

El crecimiento físico de la ciudad provoca una perdida de cobertura vegetal y la fragmentación de los ecosistemas, lo que, sumado a la contaminación por residuos, llega a causar daños irreparables a su biodiversidad.
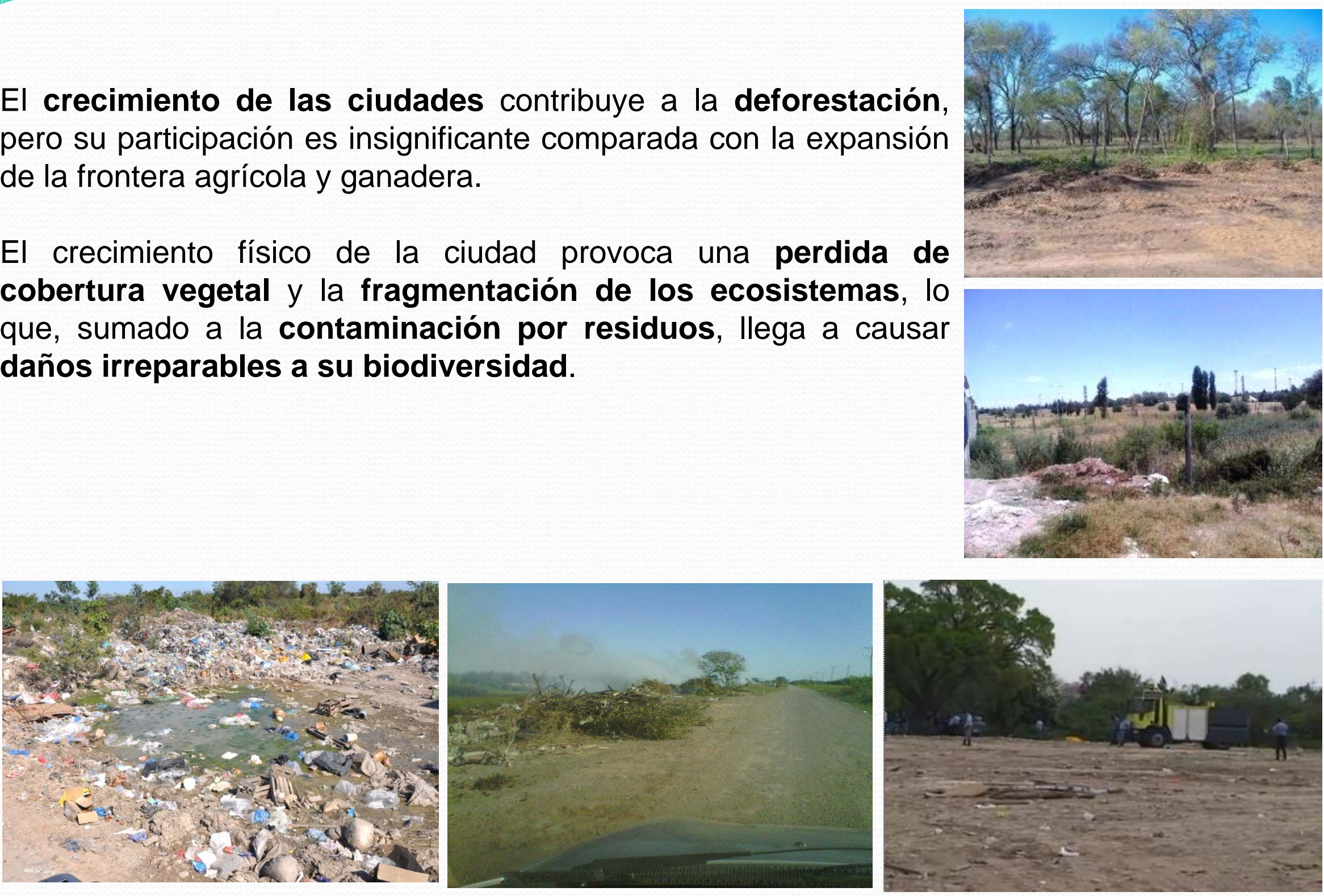
Aunque en la mayoría de los países la extracción de agua dulce está destinada principal-mente a la agricultura, las ciudades pueden ser grandes demandantes para usos residenciales, comerciales e industriales. La demanda de agua en las áreas urbanas tiende a crecer como resultado del aumento de población y, especialmente, de un mayor consumo per cápita. Se calcula que la demanda de agua se incrementó el $76 \%$ en un periodo de 15 años.

A la explotación excesiva del agua disponible, se suma la contaminación del recurso por vertimiento de aguas residuales, que, reciben poco tratamiento. Muchos de los ríos urbanos se han convertido en alcantarillado a cielo abierto, un problema que ha ganado reconocimiento y que algunas ciudades comienzan a afrontar con proyectos integrales de recuperación.
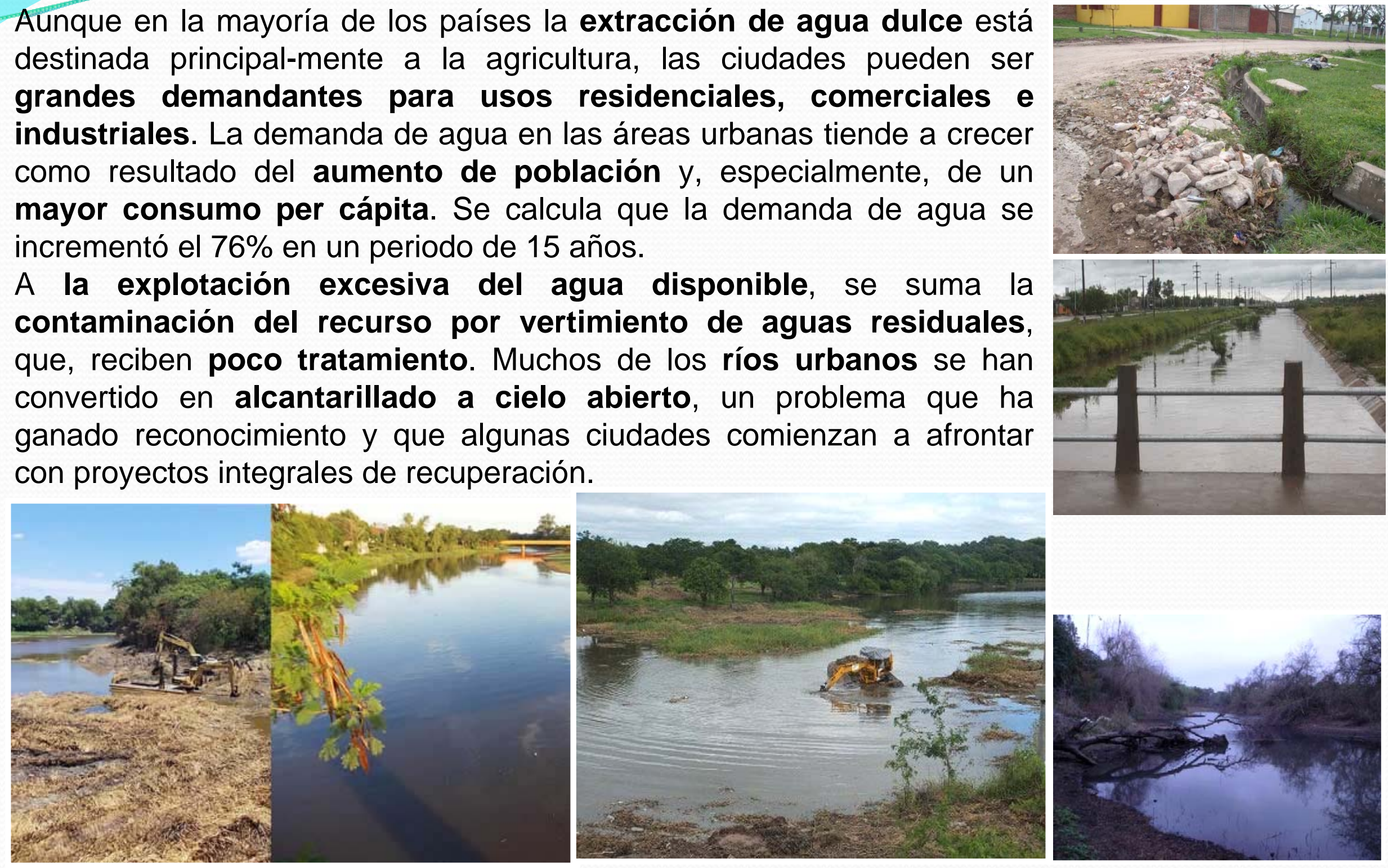

http://www.chacofederal.com/vernota.asp?id_noticia=1811 
La calidad del aire en las grandes aglomeraciones es motivo de preocupación. Muchas ciudades sufren por la presencia excesiva en su atmósfera de minúsculas partículas, como polen, cenizas, polvo de minerales, cemento y metal.

La presencia de estas partículas, denominadas por los especialistas "PM10" en referencia a su tamaño de hasta 10 micrómetros, tiene impactos nocivos sobre la salud. Los científicos han asociado la alta concentración de PM10 con enfermedades cardiovasculares y respiratorias y con una mayor morbilidad y mortalidad.

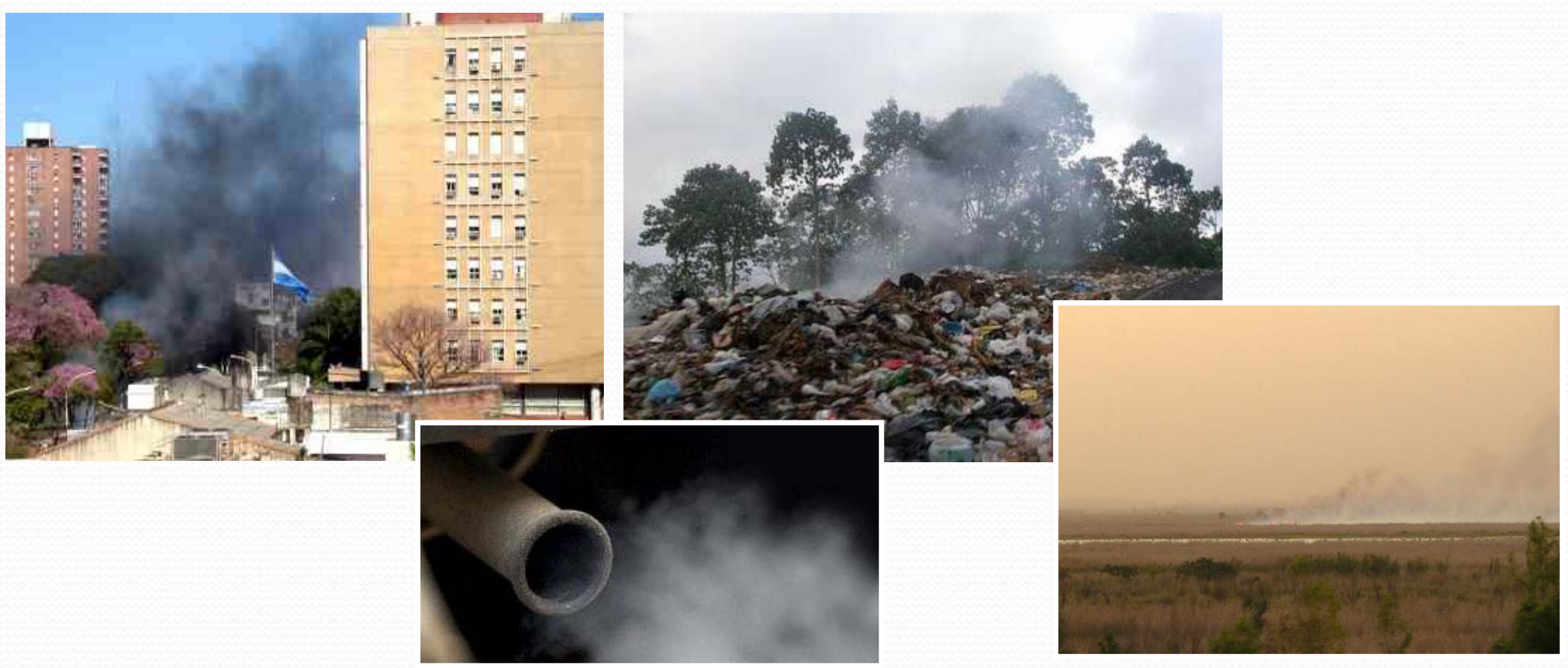




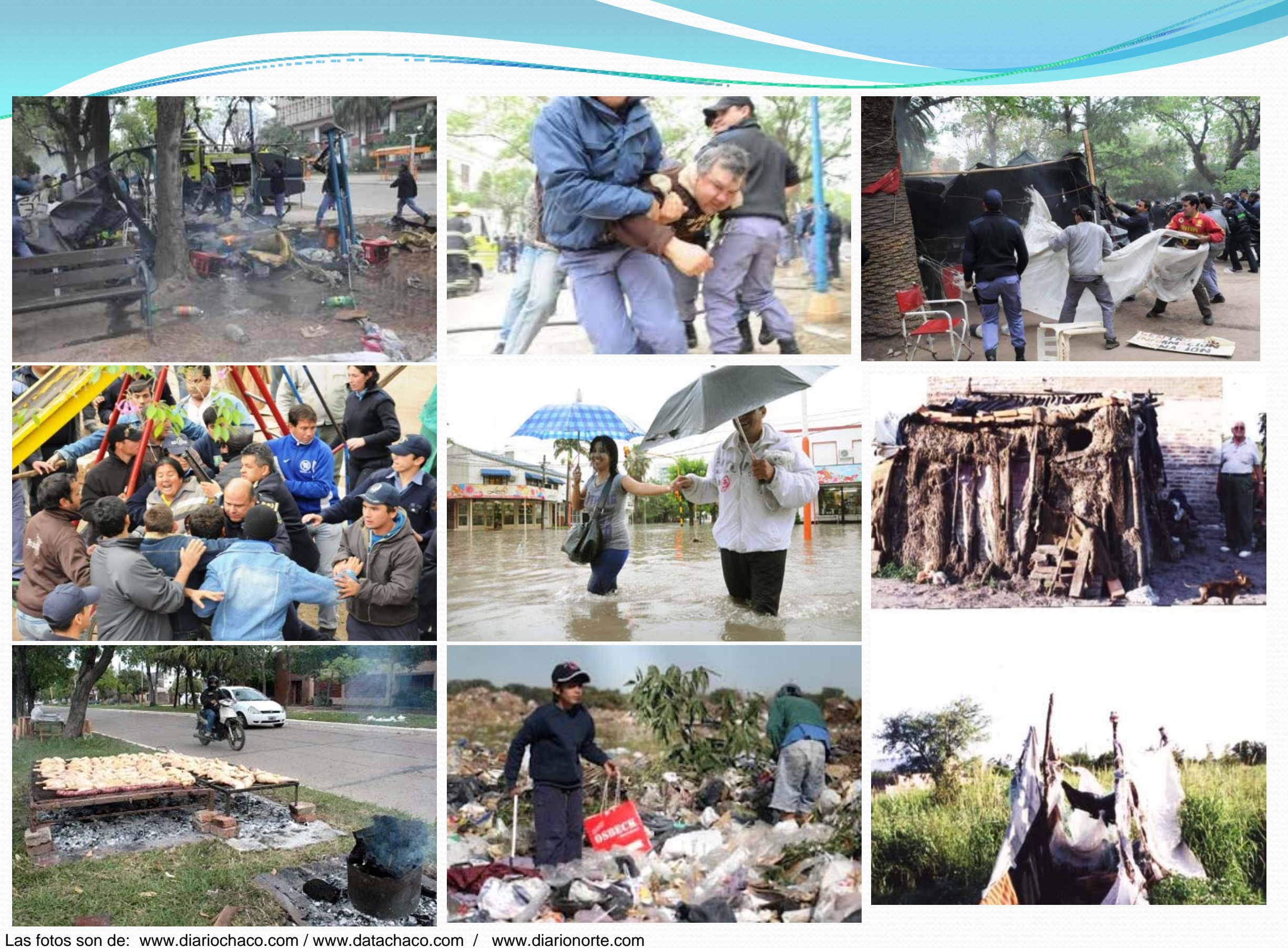




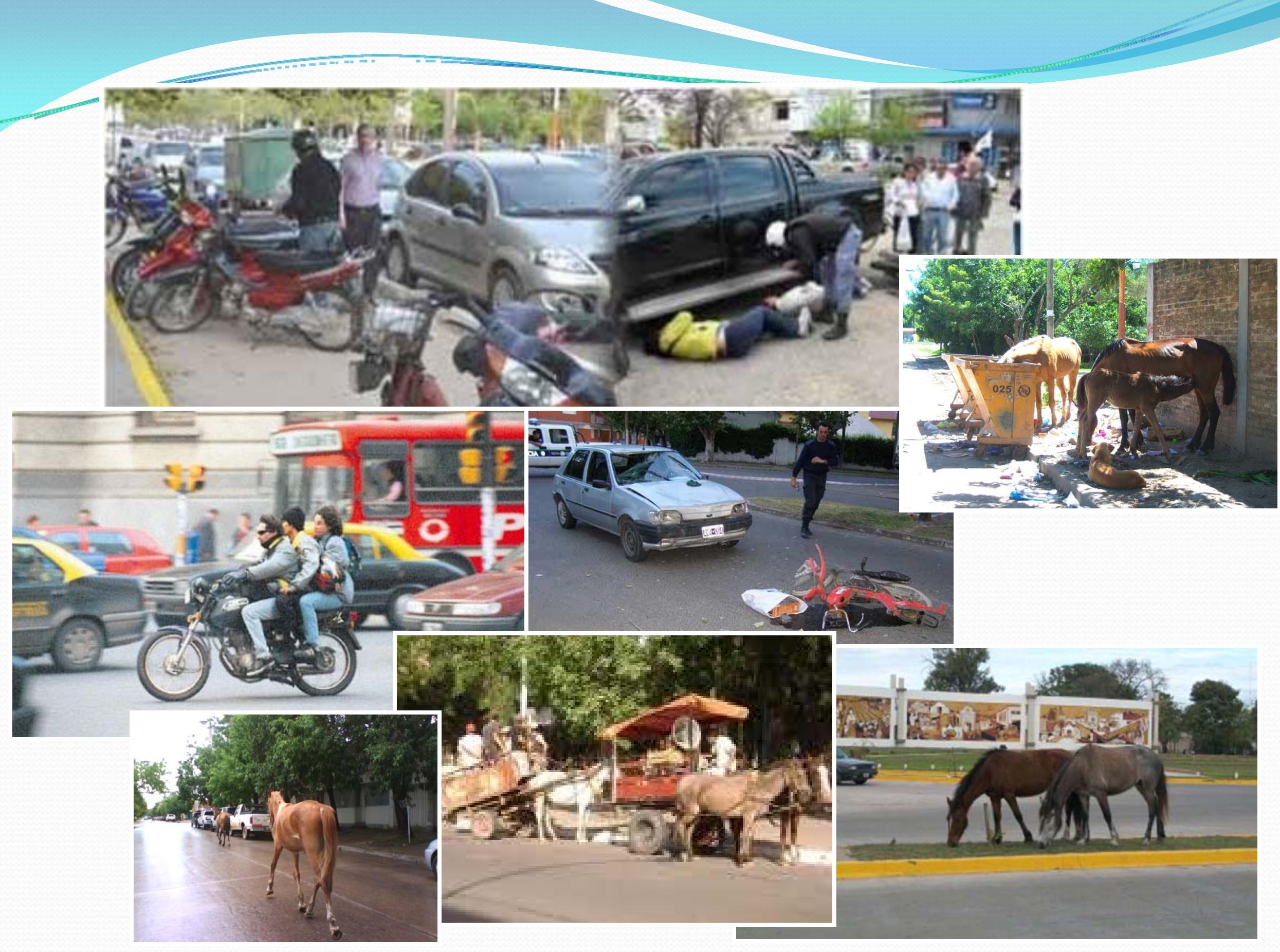



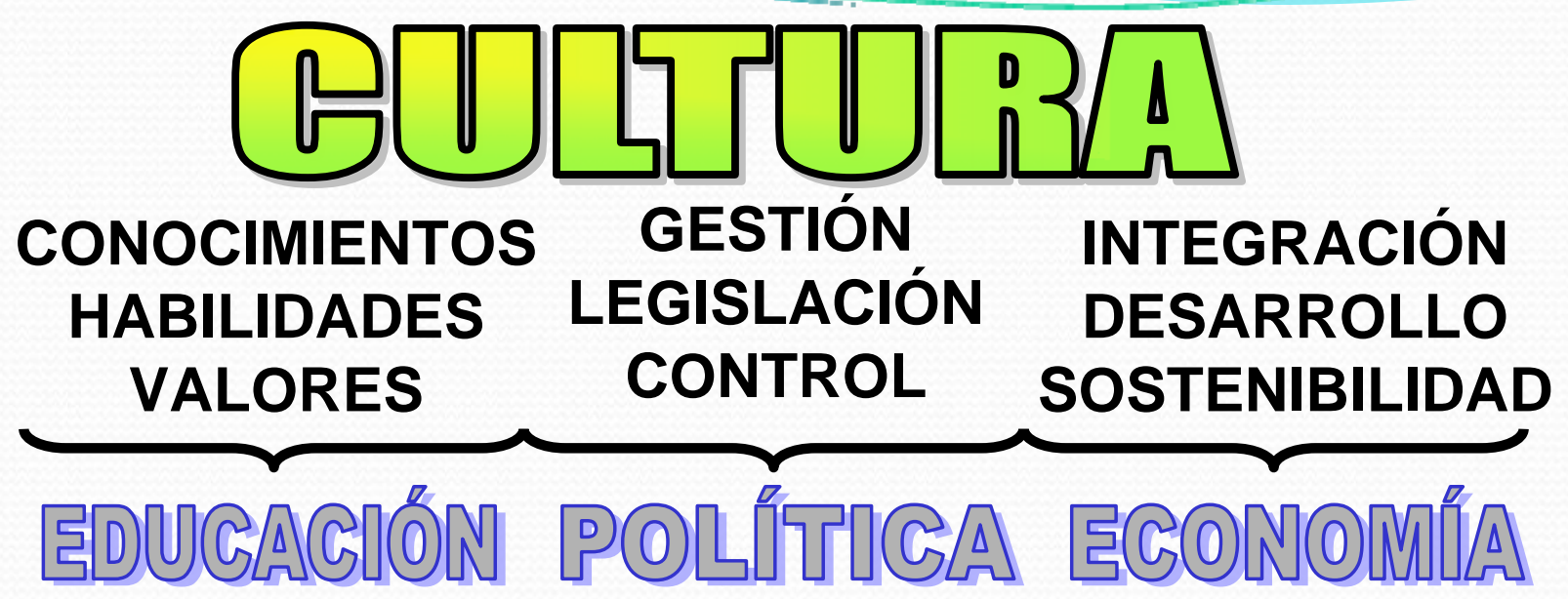

CONSUMO INFORMACIÓN ESPECULACIÓN CORRUPCIÓN

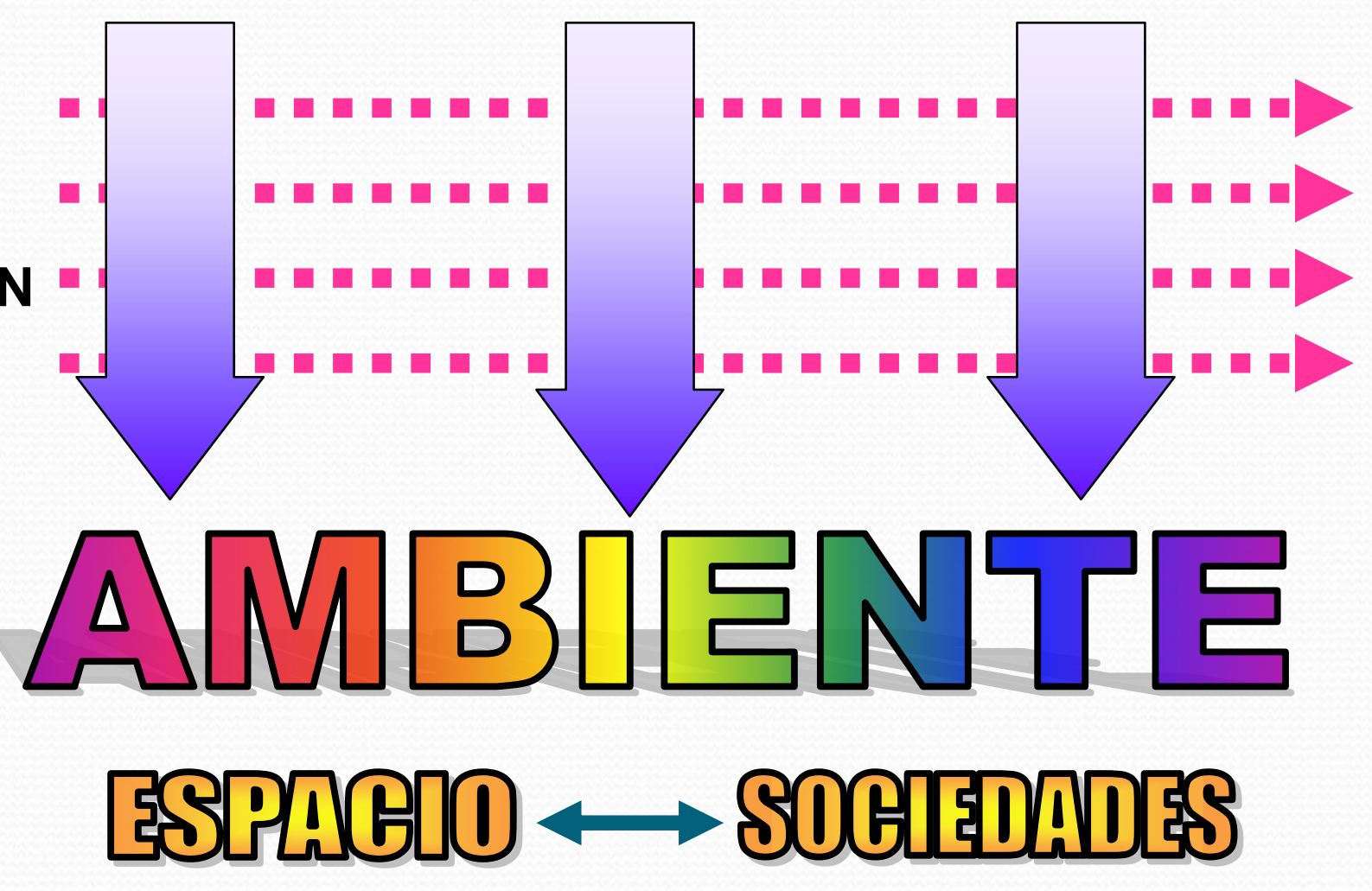




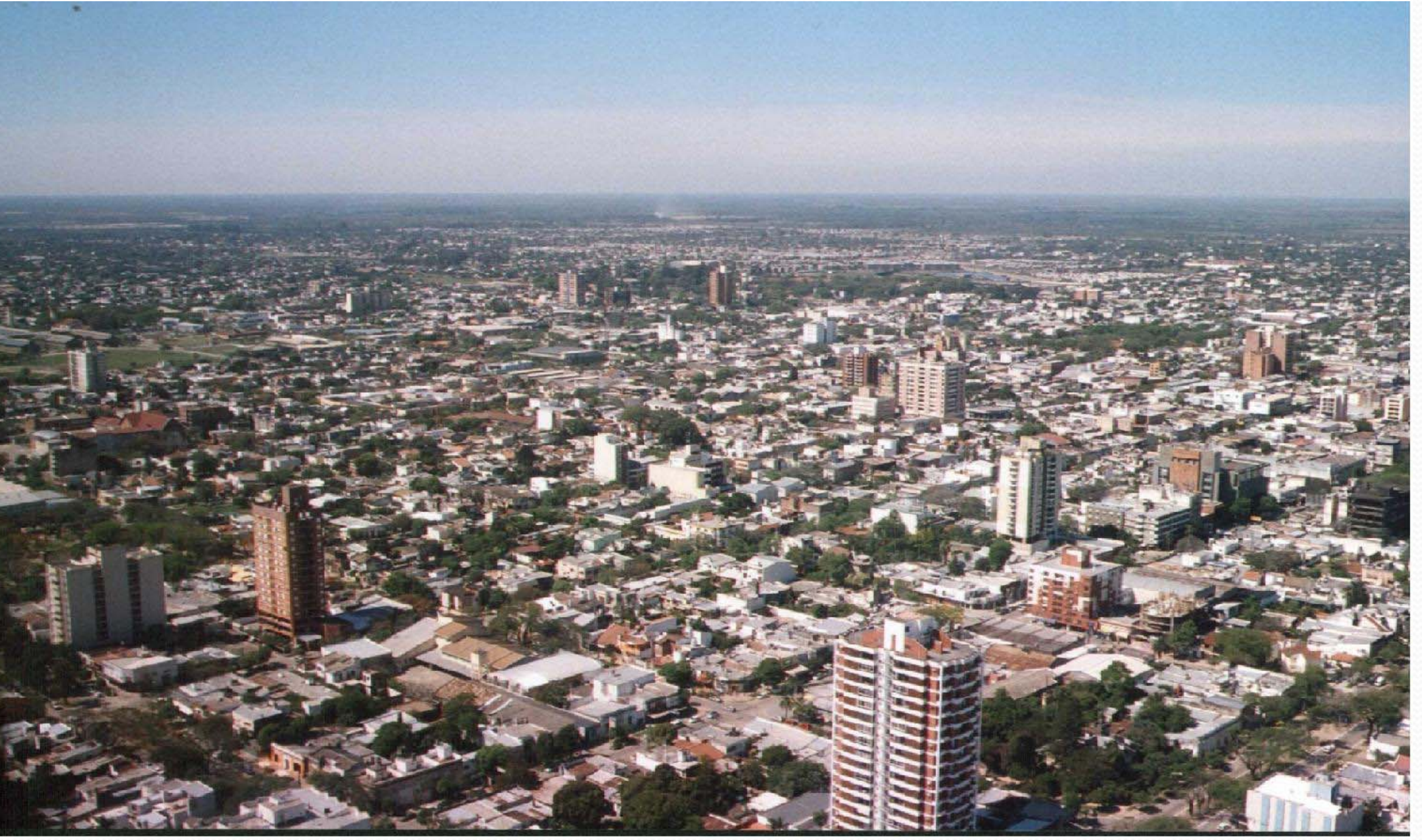




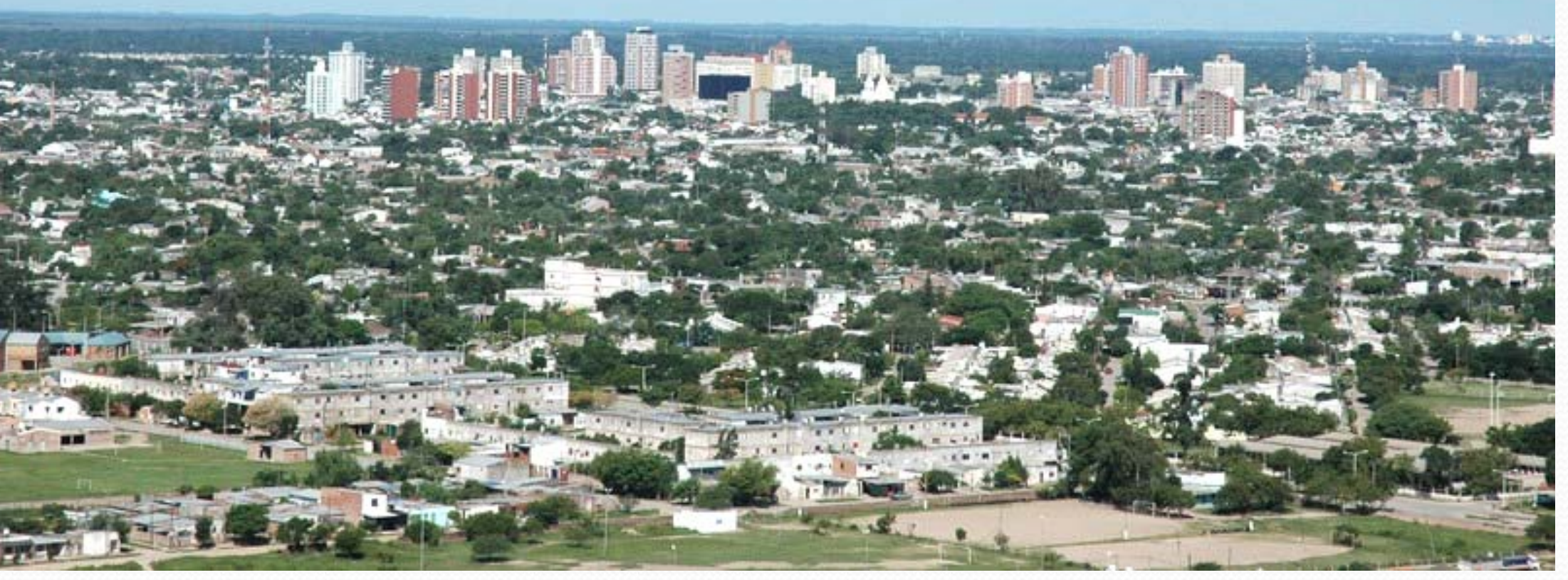

Publicado en formato digital: Prof. Juan Antonio Alberto. Urbanización e Impactos. Paisajes Resultantes . Resúmenes. Revista Geográfica Digital. IGUNNE. Facultad de Humanidades. UNNE. Año 10. № 20. Julio-Diciembre 2013. ISSN 1668-5180 . Resistencia, Chaco. En: http://hum.unne.edu.ar/revistas/geoweb/default.htm 


\section{Bibliografía:}

http://previewlibros.grupo-sm.com/33C7667D-6AF4-4818-8ABE-D12CF615B31F.html http://www.ecologiahoy.com/

http://www.revistaambienta.es/WebAmbienta/marm/Dinamicas/pdfs/versionpdf/Urbanos.pdf

http://www.secundaria.profes.net/contenidoGUID/239A0E9E-B07D-48E4-AC4F-93AC345F1E0B.html http://www.un.org/Pubs/CyberSchoolBus/spanish/cities/eun06pg01.htm

Programa de las Naciones Unidas para los Asentamientos Humanos, ONU-Hábitat. (2012). ESTADO

DE LAS CIUDADES DE AMÉRICA LATINA Y EL CARIBE 2012. Rumbo a una nueva transición urbana. En: www.unhabitat.org 